3. Versuch, statt 0.032 gefunden $0.031107=97.20 \mathrm{pCt}$.

4. - - $\quad$ - $\quad 0.03144=98.37$ -

5. $\quad-\quad-\quad-\quad-0.031398=98.17$ -

No. 1 der Versuche ist bei Gegenwart von Erythrit, No. 2 bei Gegenwart von Erythrit und Chlorcalcium, No. 5 bei Gegenwart von Erythrit, Chlorealcium und etwas färbender Substanz - Zuckercouleur - angestellt.

Die Methode giebt, wie aus den Versuchszahlen ersichtlich, genügend genau übereinstimmende Zahlen, wenn sie auch, was die Schärfe der Zahlen anbetrifft, hinter vielen maassanalytischen Methoden zurückstelt.

Wie ich leider nur an einer mir zur Verfügung stehenden Flechtenart constatiren konnte, gestattet die Methode, in einem Zeitraume von wenigen Stunden den Orcingehalt fast genau äbereinstimmend mit der quantitativen Gewichtsanalyse zu ermitteln. Die Methode für die Praxis zu gestalten will ich mir in nächster Zeit angelegen sein lassen, und ich behalte mir, indem ich diese Mittheilung nur als eine vorläufige betrachte, vor, der Gesellschaft seiner Zeit ausführlicher darüber zu berichten.

Chem. Laboratorium der Kaiserl, techn. Schule zu Moskau.

\title{
II. Vorkommen von Bromoform im käuflichen Brom, Prüfung des Letzteren auf Ersteres.
}

Beim Stellen des Titers des Bromwassers fiel cinerseits ein eigenthämlicher, an Chloroform erinnernder Geruch auf, der sich stets nach dem Titriren des aus dem Jodkalium ausgeschiedenen Jods mit unterschwefligsaurem Natron geltend machte, andererseits befremdete der Umstand, dass das gesättigte Bromwasser viel weniger Brom enthielt, als bei der beobachteten Temperatur zu erwarten war. Es waren dieses genügende Gründe, um an der Reinheit des Broms zu zweifeln. In der That ergab eine nähere Untersuchung das Resultat, dass das Brom nicht weniger als $10 \mathrm{pCt}$. eines fremden von 80 bis $165^{\circ}$ siedenden Körpers enthielt, der, wie sich nach sehr häufigem Fractioniren herausstellte, seiner Hauptmenge nach aus Bromoform bestand, dem noch ein bedeutend niedriger siedender Körper beigemengt war. Offenbar ist dies dasselbe Gemenge, wie es Hermann ${ }^{1}$ ) ans dem bei der ersten Destillation des Broms ans den Mutterlaugen in der ersten Vorlage verdichteten Gemenge isolirte, in welchem er, wie aus der Abhandlung hervorgeht, nicht ohne Schwierigkeiten das Bromoform nachwies. Das von mir isolirte Gemenge lieferte schon nach unge-

1) Hermann, Annal. der Chem. u. Pharm. XCV, 211. 
fähr dreissigmaligem Fractioniren eine genügende Menge rollkommen reinen Bromoforms.

Das Brom, einen Körper, der von Chemikern, die auf dem Gebiete der organischen Chemie arbeiten, eine sehr häufige Anwendung erfährt, sollte man nie verabsäumen, einer Prüfung auf Bromoform zu unterziehen, zumal die Gegenwart von Bromoform bei vielen Arbeiten sehr binderlich sein dürfte. Die Prüfung ist in wenigen Minuten zu bewerkstelligen.

Ein zu niedriger Gehalt des gesättigten Bromwassers an Brom, sowie der charakteristische Geruch von Bromoform, der besonders stark hervortritt, wenn man statt des Bromwassers Brom in Substanz mit einer Lösung von Jodkalium zusammenbringt und das ausgeschiedene Jod mit unterschwefligsaurem Natron entfärbt, sind ein sicherer Beweis der Anwesenbeit von Bromoform im Brom.

Chem. Laboratorium der Kaiserl. techn. Schule zu Moskau.

\section{Edmund ter Meer: Ueber Dinitroäthan.}

(Eingegangen am 10. Juni; verlesen in der Sitzung von Hrn. Oppenheim.)

Versetzt man die gelbgefärbte Mischung von 19 Theilen Monobromnitroäthan, etwas Alkohol und einer concentrirten Lösung von 11 Theilen Kaliumnitrit in Wasser allmählich unter Schütteln mit alkoholischem Kali, so wird die Farbe dunkler, und alsbald scheiden sich unter starkem Erwärmen glänzende, gelbe Krystalle nebst Bromkalium ab. Alkoholisches Kali wird eingetragen bis die Flüssigkeit alkalisch reagirt und der beftige, zu Thränen reizende Geruch des Monobromnitroaethans verschwunden ist. Nach dem Erkalten wird mittelst der Luftpumpe abfiltrirt, die Krystalle gut mit Alkohol und Aether ausgewaschen und aus möglichst wenig heissem Wasser umkrystallisirt. Die entstehenden, schönen, sehr explosiven, gelben Krystalle sind so leicht vom Bromkalium za trennen. Sie sind bromfrei; die Analysen ergeben die Formel $\mathrm{C}_{2} \mathrm{H}_{3} \mathrm{~N}_{2} \mathrm{O}_{4} \mathrm{~K}$. Die Reaction verläuft nach der Gleichnng:

$$
\begin{aligned}
& \mathrm{C} \mathrm{H}_{3} \\
& \text { C }\left(\mathrm{N} \mathrm{O}_{2}\right) \mathrm{Br} \mathrm{H} \\
& +\mathrm{KNO}_{2}+\mathrm{KHO} \\
& =\underset{\mathrm{C}\left(\mathrm{N} \mathrm{O}_{2}\right)_{2} \mathrm{~K}}{\mathrm{CH}_{3}}+\mathrm{K} \mathrm{Br}+\mathrm{H}_{2} \mathrm{O} \text {. }
\end{aligned}
$$

Der enstandene Körper ist Dinitroaethankalium (Analyse IV.) . 